\title{
THE COMPETENCY BASE OF SOCIAL WORKERS WITH REGARD TO ATTACHMENT THEORY IN FOSTER CARE SUPERVISION: A PILOT STUDY
}

\section{Wezet Botes, Elma Ryke}

\section{PROBLEM STATEMENT}

Children entering the foster care system often experience attachment difficulties due to exposure to traumatic experiences while in the care of their parents or other caregivers (Harden, 2004:11; Howe, Brandon, Hinings \& Schofield, 1999:62; May, 2005:81). Traumatised children tend to present behavioural difficulties, which could range from mild to severe, and could include oppositional defiant disorder, hyperactivity, depression and eating disorders (Harden, 2004:14; May, 2005:83; Sheperis, Blanchard, Doggett, Hoda, Renfro-Michel \& Schlagheck, 2003:32). They tend to exhibit developmental delays and school-related problems, which make them more demanding on the resources of the foster parents (Doggett, Renfro-Michel \& Sheperis, 2003:106; Sheperis et al., 2003:33). Many such placements eventually collapse because the underlying issues which lead these children to form ineffective attachment patterns are not addressed (Green, 2003:209; Harden, 2004:35).

Since the original development of attachment theory by Bowlby (1969), various related theories and applications focusing on the attachment between parents and children have been developed. In recent years the theory has also been applied to the social work fields of adoption and foster care (Peluso, Peluso, Kern \& White, 2004:139). From the latter it became apparent that a better understanding of attachment-related issues by the social workers that do foster placements and supervision may have a positive impact on placement stability (Chamberlain, Smith, Stormshak \& Bridges-Whaley, 2001:201).

The question has arisen whether South African social workers in the field of foster care are aware of the new developments in attachment theory and if they consider issues related to attachment when placing children in alternative care. Associated with this is the question of whether or not social workers are equipped with the foundational concepts of attachment theory.

\section{RESEARCH AIM}

The research aim was to explore the extent of social workers' knowledge and practical application regarding foundational concepts of attachment theory, and what they perceived their knowledge and use in practice to be in the context of foster care supervision.

\section{RESEARCH METHOD}

A survey of the knowledge and practical application of social workers regarding attachment theory in foster care supervision is at the core of this research project. The methodological parameters are outlined below.

\section{RESEARCH DESIGN}

A quantitative-descriptive (survey) design (Fouché \& De Vos, 2005:137) was used to do explorative research. 


\section{MEASURING INSTRUMENT AND DATA COLLECTION}

The researchers developed a four-part questionnaire that captured the demographic description, training background, knowledge of the theoretical components of attachment theory, and the social workers' experiences related to attachment in foster placements. An attempt was made to construct the measuring instrument with a high level of validity and reliability (Delport, 2005:160-163). Telephonic interviews were utilised because of their cost efficiency and the availability and accessibility of the research respondents. The respondents were located at various community-based offices across the Tshwane Metropolitan area, which made the logistics of conducting face-to-face interviews impractical.

\section{SAMPLING AND CRITERIA FOR RESEARCH RESPONDENTS}

From a population of 38 social workers employed by Child Welfare Tshwane, the 18 social workers who dealt with foster care placement supervision and assessment were identified as candidates for the research. Of these, 17 participated in the study, including three social workers in residential care facilities, four doing therapy and assessments, and ten foster care supervision.

\section{DATA PROCESSING}

The questionnaire was developed within the parameters of the data analysis software for easy capturing and processing. The researchers made use of a computerised data analysis programme to do the initial data processing. The statistical processing was done by Statistical Consultation Services of the North-West University and further processed by a privately hired research psychologist. The results are visually represented in tables and graphs for further interpretation in the light of the current academic discourses.

\section{LIMITATIONS}

The population selection (only social workers from Child Welfare Tshwane) and sample size $(n=17)$ may have negatively impacted on the validity of the study. The researcher was limited by time and accessibility, and therefore had to make some sacrifices to be able to generalise the results of the study. A more representative sample reflecting the larger social work population may have yielded different results. Therefore this study at most serves the purpose of a pilot study. The group of social workers who had 0-3 years of experience were also over-represented in the sample. This phenomenon reflects an organisational constraint within Child Welfare Tshwane which might not be applicable to all other welfare organisations. The data-collection method of telephonic interviews posed a further difficulty. Some of the respondents found it difficult to recognise some of the terminology of the theoretical component of attachment theory and a face-to-face interview may have presented fewer constraints. The researchers compensated for this limitation by conducting the interviews personally, which made it possible to adapt the pace of the interview and clarify the questions to the respondents in order to facilitate accurate data collection.

The study also researched the perceptions of the social workers regarding their knowledge and use of attachment theory, but their actual in-practice use was not independently assessed as a control measure. This constraint was addressed to a certain extent by triangulating the theoretical component of "knowledge" and "use" with the "in-practice" statements concerning the respondents' understanding and application of attachment theory. It also seemed that the respondents over-estimated their own knowledge and use of attachment theory in the selfevaluation questions, which led to large discrepancies between the theoretical component questions and the self-evaluation statement scores. 


\section{THEORETICAL REVIEW OF ATTACHMENT THEORY}

\section{ORIGIN OF ATTACHMENT THEORY AND MAJOR CONTRIBUTORS}

Attachment theory was originally developed by John Bowlby as a branch of psychoanalytic theory (Peluso et al., 2004:139) during the 1950s and 1960s (Bowlby, 1969). He described the formation of the bond between a mother and an infant and the significance this bond has in terms of its lasting impact on the life of the child and, on a larger scale, the survival of the human species. Bowlby conceptualises attachment as a biological drive towards species survival. He theorised that attachment to a primary care giver (mother) provided protection from predators and a safe environment for the infant to explore the world. In doing so, he revolutionised thinking about a child's tie to a caregiver and the effects of disruption through separation and deprivation (Bowlby, 1969).

Attachment theory was extended and its concepts refined by various contributors such as Ainsworth, Belhar, Waters and Wall (1978), who took Bowlby's theory, developed it further and made it more applicable by categorising attachment relationships as secure and insecure thus formulating the concept of attachment patterns. Two further patterns of attachment, namely insecure-avoidant and insecure-ambivalent patterns, were identified. They also developed the "strange situation" as an assessment method to determine the attachment patterns of a child (Peluso et al., 2004:139).

Belsky and Nezworski (1988) and Sroufe (1988) contributed by describing the correlation between the quality of care that the infant received and the quality of the attachment relationship between the child and care giver. This became a basic assumption within the theory. In this study the phrase attachment theory is used to refer to the larger theoretical body of knowledge associated with developments in the field of attachment, and not only to the work of the above-mentioned contributors. As a result of new research attachment theory is constantly developing (Department of Community Services, NSW, 2006:2); therefore it would not be possible to give an overview of all the concepts of this theory in this article. What follows is a discussion on the key theoretical components used in this research paper.

\section{BASIC ASSUMPTIONS AND THEORETICAL CONSTRUCTS}

Attachment could be defined as the "enduring emotional bond that exists between a child and a primary caregiver, who could be a biological parent or an unrelated caregiver" (Harden, 2004:31; Sheperis et al., 2003:13). Bowlby suggested that attachment had a protective and instructive function, where the mother kept the infant close for protection in the presence of danger, but in the absence of danger the infant used the mother as a secure base from which to explore the world (Peluso et al., 2004:139-140). The interaction between the mother (or primary caregiver) and the child forms the child's basic expectation of other relationships and its place in the world.

The need to attach is a universal occurrence (Harden, 2004:30). How these attachments are formed and what qualities are deemed important is influenced by the values of a specific culture (Haight, Kagel, \& Black, 2003:196-201). Most of the research on attachment has been done with Western European samples and so scholars have indicated the need to research attachment presentations in non-Western cultures. Cultural differences are under-represented in the body of knowledge regarding attachment (Haight et al., 2003:201). Research has indicated that adequate attachments are needed for healthy development (Haight et al., 2003:195). Attachment formation occurs in the infant from birth to about 18 months. By 24 months the 
child would have established his or her attachment pattern and would have come to some conclusion about the self and the world: either as positive or negative (Haight et al., 2003:198).

If these interactions were good and the child had received attentive and concerned care, the child would form a secure attachment. This secure attachment is characterised by a sense of belonging and intimacy, emotional security and safety when the child is in the presence of the primary care giver (Peluso et al., 2004:140).

In contrast, an insecure attachment is formed where there was some disturbance in the interaction between carer and child such as illness, adverse circumstances or neglect. The child then does not experience a sense of emotional security and belonging, and that has a negative influence on the way the child perceives itself and the world at large. These negative perceptions may persist into adulthood (Peluso et al., 2004:140).

Three insecure attachment patterns were initially identified. The insecure-avoidant attachment pattern - children display withdrawal from the caregiver, low need for physical contact and seem emotionally distant. Their caregivers often display feelings of anger and annoyance towards the children (Peluso et al., 2004:140). Insecure ambivalent - this attachment pattern forms in the presence of inconsistent and unresponsive care, where the child remains uncertain with regard to the caregiver's reaction. The child experiences internal conflict regarding the availability and care of the parent. Such children show "inhibited exploration and the preoccupation with self-protection, while showing increased recklessness and accident proneness" (Lieberman \& Pawl, 1988; Sroufe, 1988 in Peluso et al., 2004:140). A fourth attachment pattern, insecure-disorganised, was later described by Sagi et al. (1994) (in Haight et al., 2003:202), whereby a child is unable to form a predictive expectation of the carer's interaction where the carer has displayed frightened or frightening interactions with the child. This pattern has been shown to be prevalent among children who have been exposed to severe neglect and abuse (Haight et al., 2003:202).

Another attachment pattern that has emerged more recently in the literature is insecureindiscriminate attachment. In this pattern the child had experienced several primary carers during infancy and had failed to form a significant attachment with any of them. Indiscriminate attachment has been linked to reactive attachment disorder (Newman \& Mares, 2007:344). The relational patterns are superficial and usually short-lived. Young children in the foster care system are particularly vulnerable to the formation of this attachment pattern.

By the age of three years a child would have internalised and established his or her attachment pattern. These internalised expectations are then transferred to relationships and form a blueprint for future interactions. The experience of self and the world stabilises and an internal working model is established (Ackerman \& Dozier, 2005:508; May, 2005:82). This model will "shape an individual's behaviour, affect, ideas about self, others and relationships along the lifespan" (Howe et al., 1999:49; Peluso et al., 2004:141). The attachment patterns of a young child could be determined by the "strange situation", which is an observational assessment method first developed by Ainsworth et al. (1978) and has been tested extensively (Goossens, Van Ijzendoorn, Tavecchio \& Kroonenberg, 1986:23-32). An acceptable standardised assessment method for older children and adolescents has not yet been established (Newman \& Mares, 2007; Sheperis et al., 2003). A battery of psychological tests such as the Child Behaviour Check List developed by Achenbach (1991), Reactive Attachment Disorder Check List (Minnis, Marwick, Athur \& McLaughlin, 2006:336-342) and others, along with clinical and in-home observations, are usually employed to assess older children's attachment patterns. 
These are tests social workers may not perform and seldom have access to - this thus complicates the effective identification of attachment disorder. These researchers are of the opinion that adequate knowledge of attachment theory would enable social workers to at least become sensitive to the attachment needs of the client and to adapt services to the family accordingly.

\section{CLINICAL PRESENTATIONS}

The clinical presentation of children with attachment difficulties vary in range from mild to severe. Indications of their attachment-based problems are often manifested in their behaviour, which could lead to these children being labelled as naughty, uncontrollable and "hard to place". Maltreated children with attachment difficulties may present as being impulsive and as having low self-esteem; other indicators are emotional instability, poor school performance, having difficulty with abstract concepts and poor conscience development (May, 2005:81).

A child with severe attachment difficulties could be diagnosed - based on the Diagnostic and Statistical Manual of Mental Disorders IV, Text Revised (Newman \& Mares, 2007:343) - as having reactive attachment disorder (RAD). The disorder is defined as "markedly disturbed and developmentally inappropriate social relatedness in most contexts and begins before age 5 years and is associated with grossly pathological care" (DSM-IV-TR, 2004:127). Sheperis et al. (2003:291) and Newman and Mares (2007:343-345) elaborate on the difficulty in diagnosing reactive attachment disorder, arguing that although attachment disorders are acknowledged, a standardised evaluation tool has yet to be developed to aid in effective and time-sensitive diagnosis. It is generally accepted that RAD in children is over-diagnosed and is thought to be uncommon (Newman \& Mares, 2007:343-345). Such a diagnosis is equally uncommon in the current social work service field at Child Welfare Tshwane, but undoubtedly children with this disorder would be present but largely unidentified in foster care caseloads. Attachment-related problems are also indicated when children display over-vigilant or overly compliant behaviour, and show indiscriminate connection to every adult, or do not demonstrate attachment behaviour (Harden, 2004:35).

\section{APPLICATION IN THE SOCIAL WORK FIELD}

Attachment theory holds specific application potential in social work services to children. It has a bearing on child-protective services and alternative care situations such as foster care, institutionalised care and adoptions by providing a framework for understanding and evaluating parent-child relationships. Attachment theory concepts "help to explain why children who had a poor start to relationships with others, or who have experienced seriously disrupted care, often behave in very troubling ways while in care" (Department of Community Services, NSW, 2006:1).

Placement disruptions have been linked to attachment difficulties (Chamberlain et al., 2001:200). A number of children in foster care have been exposed to adverse circumstances such as poverty, maltreatment and the removal from parental care, which has been linked to an array of developmental stumbling blocks including inadequate social skills, poor physical and mental health, and attachment disorders (Harden, 2004:30). Research also suggests that children in foster care are more likely to display insecure and disorganised attachments than non-foster children (Harden, 2004:34-37), and that placement instability has been associated with negative developmental outcomes. It has also been established that positive, stable and warm home environments have had a positive effect on foster children, where it has "lessened the effects of the harmful experiences by exposing them to protective factors that can promote 
resilience" (Haight et al., 2003:197; Harden, 2004:35). Children with attachment difficulties have been able to "develop positive attachment relationships with new and sensitive caregivers" (Department of Community Services NSW, 2006:7).

The need for sensitive social work supervision and support to foster care placements has also been underscored in the literature. Harden (2004, 37-38) indicated that placement stability was influenced by the case worker-foster parent relationship and that welfare agencies have fulfilled an important role in ensuring that the child's individual needs are met (Harden, 2004:42; Stone $\&$ Stone, 1983). A noteworthy finding of current research is that it seems possible to "maintain contact with the birth parents without compromising the developments of new attachments while in foster care" (Howe et al., 1999:671-687, in Department of Community Services NSW, 2006:4). Findings such as these could make a difference in the way contact with the biological parents is viewed in foster care supervision and could strengthen the argument for current training on attachment theory. A comprehensive service, attending to the child and foster parent attachment needs and providing adequate support, has the potential to enrich the foster care experience and could mitigate the occurrence of placement collapse.

\section{ATTACHMENT THERAPIES}

Attachment therapies attempt to address the problematic behaviour of a child by improving the attachment relationship between the primary caregiver and the child. "Such therapies seek to repair a break in the need cycle by confronting the child, identifying and breaking down psychological defences and repairing the trust of the child through a combination of holding and nurturing touch" (Attach, 2004 in Barth, Crea, John, Thoburn \& Qiunton, 2005:260). These therapies have different approaches and show convergence of various modalities, such as theraplay, which combines play therapy with attachment principles (Jenberg \& Booth, 2005), and family attachment narrative therapy, which uses narratives as part of the therapeutic process (May, 2005:81-99).

Holding therapy is one of the better-known attachment therapies, but has come under increasing criticism for its seemingly "coercive and forceful" holding of the child (Barth et al., 2005:260; Newman \& Mares, 2007:345-346). Scholars recognise that attachment therapies have been found to be effective in altering parental sensitivity and behavioural symptoms in infants and young children (Velderman et al., 2006 in Newman \& Mares, 2007:345-346).

\section{LIMITATIONS OF THE THEORY}

Attachment theory and its application have come under the scrutiny of other schools of thought in psychology, who argue that attachment theory and especially attachment therapy, has become an umbrella term to diagnose and treat behaviour that could also be understood from different frameworks (Barth et al., 2005:265). They also argue that the application of attachment theory in the field of child services has outpaced the theoretical and empirical support for these interventions (Barth et al., 2005:257). It would seem that attachment theory could identify and address an array of behaviours among the children whom social workers routinely deal with, and it may be tempting to interpret all these symptoms in terms of attachment. These researchers caution that one should not see attachment theory as a "silver bullet" to change barely functioning foster placements into havens of emotional security overnight, but state that it can offer valuable insight into the family dynamics present and lead to more sensitive service delivery. 


\section{RESULTS}

The research results are discussed with reference to the demographic description, educational and experiential background of respondents, knowledge and use of the theoretical components, and self-evaluation of application of attachment theory.

\section{DEMOGRAPHICS}

\section{TABLE 1}

AGE DISTRIBUTION OF THE RESEARCH PARTICIPANTS

\begin{tabular}{|l|c|c|c|}
\hline & Mean & Min. & Max. \\
\hline Age $(\mathrm{n}=17)$ & 36 & 22 & 65 \\
\hline
\end{tabular}

All the respondents were women and they ranged in age from 22 to 65 years with a mean age of 36 years. The respondents represented nine of the ten community-based offices and residential facilities of operation of the organisation. The areas included Attridgeville (12\%), Bramley Children's Home (12\%), Centurion (6\%), Eersterust (12\%), Elandspoort (12\%), Itumeleng shelter for street children (6\%), Mamelodi (12\%), Olivenhoutbosch (6\%) and the Therapy Unit (24\%). The racial distribution reflected that of the organisation at large and that of the communities the organisation serviced. The black population group had the highest representation $(53 \%)$ in the study.

TABLE 2

RACIAL DISTRIBUTION OF RESEARCH PARTICIPANTS

\begin{tabular}{|l|c|c|c|c|}
\hline Race $(\mathbf{n}=\mathbf{1 7})$ & Black & Coloured & Indian & White \\
\hline Percentage & 53 & 6 & 6 & 35 \\
\hline
\end{tabular}

\section{EDUCATION AND YEARS OF EXPERIENCE}

The education level and years of experience of the respondents had significance for the study, since this was identified as the possible sources of information regarding attachment theory. In South Africa legislation prescribes that a four-year university degree or a three-year degree with an Honours Degree is a requirement to practise as a social worker. Ninety-four percent (94\%) of the respondents were university graduates and $24 \%$ had completed postgraduate studies. One respondent (6\%) had not yet graduated. A total of $41 \%$ reported that they had received post-qualification training regarding attachment theory.

\section{TABLE 3}

TERTIARY EDUCATION OF RESPONDENTS

\begin{tabular}{|l|c|c|c|c|}
\hline $\begin{array}{c}\text { Research Partici- } \\
\text { pants (n=17) }\end{array}$ & $\begin{array}{c}\text { Under- } \\
\text { graduate }\end{array}$ & Graduate & Postgraduate & $\begin{array}{c}\text { Training included } \\
\text { Attachment Theory }\end{array}$ \\
\hline Percentage & 6 & 94 & 24 & 41 \\
\hline
\end{tabular}

Nine universities were represented in the study: University of South Africa (Unisa) (29\%), University of Pretoria (24\%), Huguenot College (12\%), University of the Free State (6\%), University of Johannesburg (6\%), University of Limpopo (6\%), University of KwaZulu-Natal (6\%), University of the North (6\%) and Venda University (6\%).

The group of respondents that had between nought and three years of experience as social workers was over-represented in the sample (59\%). Child Welfare Tshwane had experienced a 
high turnover of staff, and unfortunately more experienced social workers had been lured away by government departments and the private sector.

TABLE 4

YEARS OF EXPERIENCE OF THE RESEARCH PARTICIPANTS

\begin{tabular}{|l|c|c|c|c|c|}
\hline \multicolumn{1}{|c|}{ Experience } & $\mathbf{1 - 3}$ Years & 4-6 Years & $\mathbf{7 - 9}$ Years & $\mathbf{1 0 - 1 2}$ Years & $\mathbf{1 2}$ \\
\hline Social work experience & $59 \%$ & $6 \%$ & $6 \%$ & $12 \%$ & $18 \%$ \\
\hline Foster care experience & $82 \%$ & $12 \%$ & $6 \%$ & $0 \%$ & $0 \%$ \\
\hline
\end{tabular}

There was also a shortage of experienced social workers who were in a position to hire newly qualified workers. The group of respondents who had between nought and three years of experience in the foster care field was again over-represented in the sample (82\%). There were no respondents with more than nine years of experience in foster care. The statistics reveal a disturbing trend within the workforce, namely that those social workers who are responsible for foster care supervision seem to be young and inexperienced. It is already documented (Department of Social Development, 2005:51) that many experienced non-profit organisation personnel are lost to the private and state sectors, while at the same time an increased level of skill is required for successful performance. These organisations' capacity to deliver quality services is thus diminished. The effect that a young and inexperienced work force could have on the quality of foster care supervision services, however, has yet to be seen,

\section{KNOWLEDGE AND USE OF THEORETICAL COMPONENTS OF ATTACHMENT THEORY}

Eleven key terms and concepts associated with attachment theory were identified, namely John Bowlby, attachment theory, strange situation, attachment pattern, secure attachment, insecure attachment, avoidant attachment pattern, ambivalent attachment pattern, disorganised attachment pattern, indiscriminate attachment pattern and attachment therapy (see theoretical review for term descriptions). The respondents were then asked whether they are familiar with these terms and in which context they became familiar with them - either in university social work training, university psychology, post-qualification training or in-practice experience. Referring to the same key concepts, they were asked where they had used them in foster care supervision - either in foster care screening, supervision visits, placement assessment, report writing or panel discussions.

An average was then calculated for each one of the attachment theory terms or concepts across the two axes of knowledge and use. The results yielded lower than expected scores, with the total average of "Knowledge of theoretical components of attachment theory" being only 24\%, while the total average of "attachment theory use" was $20 \%$.

TABLE 5

TOTAL AVERAGES OF KNOWLEDGE AND USE OF ATTACHMENT THEORY THEORETICAL COMPONENTS

\begin{tabular}{|l|c|c|}
\hline Theoretical components & Average knowledge & Average use \\
\hline Percentage & $24 \%$ & $20 \%$ \\
\hline
\end{tabular}

The most commonly known and used component was the term "attachment theory" (Knowledge $=38 \%$, Use $=43 \%$ ) followed by the component "insecure attachment" (Knowledge $=35 \%$, Use $=26 \%$ ). The third most known and used component was "attachment therapy" (Knowledge $=25 \%$, Use $=30 \%$ ). The lowest scoring components were "indiscriminate 
attachment" (Knowledge $=18 \%$, Use $=10 \%)$ and the "strange situation" (Knowledge $=7 \%$, Use $=1 \%$ ). The remaining components ranged between $18 \%$ and $31 \%$ for knowledge and between $15 \%$ and $30 \%$ for use.

The low percentage scores across all the variables indicate that attachment theory may not be well known or widely used among the social workers of Child Welfare Tshwane. The components which referred to more advanced concepts of attachment theory such as the "strange situation", "avoidant", "ambivalent", "disorganised" and "indiscriminate" were scored lower on both the knowledge and use axes, which suggests that the respondents do not have a workable understanding of what attachment theory entails. This is a concern, because the increased risk of placement disruption and collapse have been positively linked to the ineffective attachment patterns of children not being addressed in foster care services (Green, 2003:209; Harden, 2004:35).

FIGURE 1

COMPARISON OF AVERAGE ATTACHMENT THEORY KNOWLEDGE AND USE

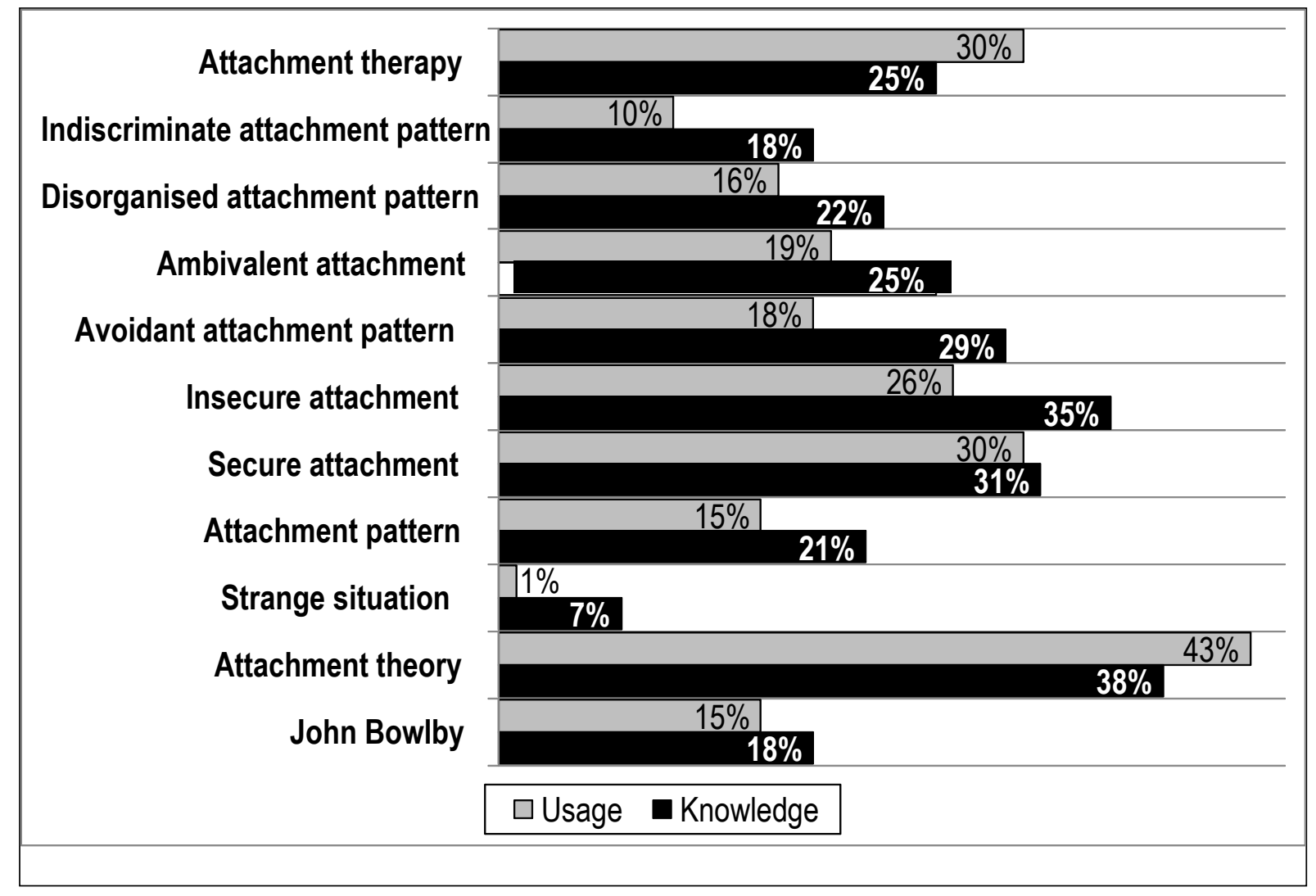

\section{SOURCES OF KNOWLEDGE REGARDING ATTACHMENT THEORY}

The study explored the respondents' exposure to attachment theory from four possible sources namely in-practice exposure, post-qualification training, university psychology and university social work graduate level studies.

Most of the respondents identified in-practice experience (35\%) as their main source of information regarding attachment theory. This is cause for concern since most of the respondents in this sample have three years of experience or less. The second source of information identified was from university psychology $(30 \%)$ followed by post-qualification training $(21 \%)$ which is usually left to the discretion of the individual to choose which training courses he/she is interested in. Their interests may or may not lie with attachment-related issues 
and therefore this source of information would not necessarily be the most effective way of training the larger social work population on attachment theory.

FIGURE 2

SOURCES OF KNOWLEDGE REGARDING ATTACHMENT THEORY

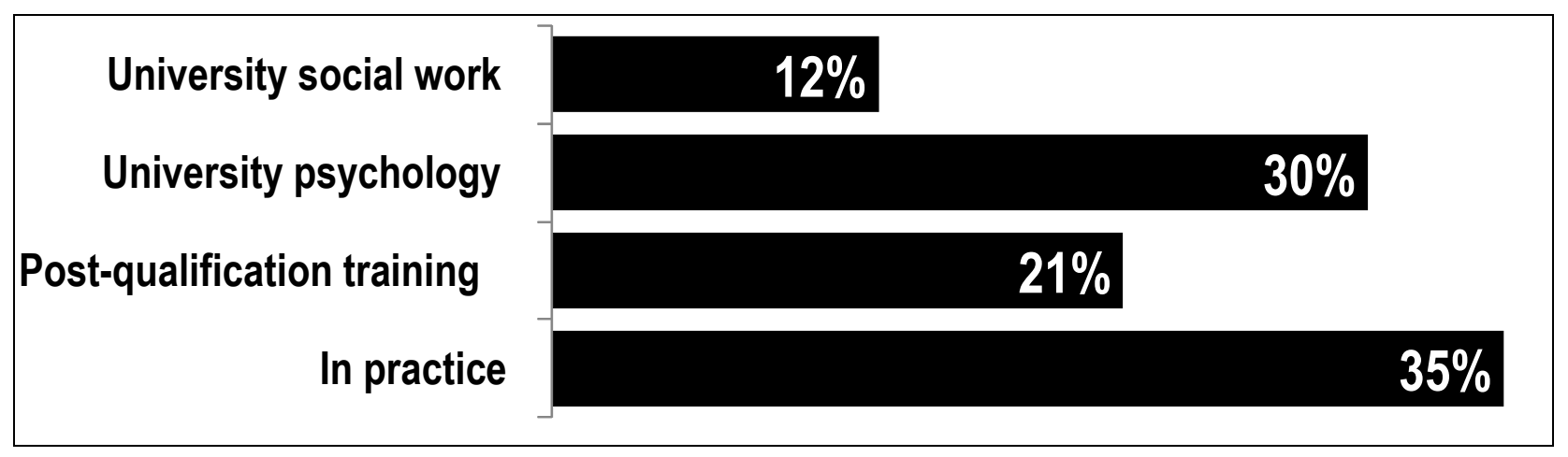

Social Work graduate studies were the lowest scoring source of information (12\%), indicating that attachment theory possibly does not receive much attention in the Social Wcurriculum. The importance of attachment theory within the social work context, especially foster care, has been established by recent research done in this field (Chamberlain et al., 2001; Department of Community Services NSW, 2006; Haight et al., 2003; Harden, 2004; Howe et al., 1999; Sheperis et al., 2003). From the current academic discourse it could be argued that the ability to evaluate and address attachment difficulties within foster care placements is necessary for effective service delivery, even at the first-time entry into practice.

\section{APPLICATION (USE) OF ATTACHMENT THEORY IN FOSTER CARE SUPERVISION}

These researchers arranged foster care supervision into five categories in which attachment theory could be used, namely:

- Foster care screening - the process of selecting prospective foster parents and matching of foster children;

- Foster care supervision visits - regular in-home contact, where the placement is monitored;

- Placement assessment - the mandatory two-year revision of the physical conditions, social and emotional wellness of the foster parents and child in order to renew the Children's Court order;

- Report writing - writing Article 16(2) reports to the Department of Social Development, or any other reports, i.e. assessment reports;

- Panel discussions - forums where the foster care placement is discussed to facilitate decision making.

The measured scores were very low (see Figure 3) and ranged between $19 \%$ and 25\%, with "foster care supervision visits" measuring the highest score of $25 \%$. "Placement assessment" scored 24\%. The research indicated that attachment theory is least used in "panel discussions" (19\%). From these measurements it could be concluded that attachment theory was in general not used in any of the researched application areas. The presence of attachment-related issues in the case loads of these social workers seemed to be largely unnoticed and the attachment 
needs of the children, as identified in attachment theory, were not taken into consideration in critical foster care supervision activities.

FIGURE 3

ATTACHMENT THEORY USED IN FOSTER CARE SUPERVISION

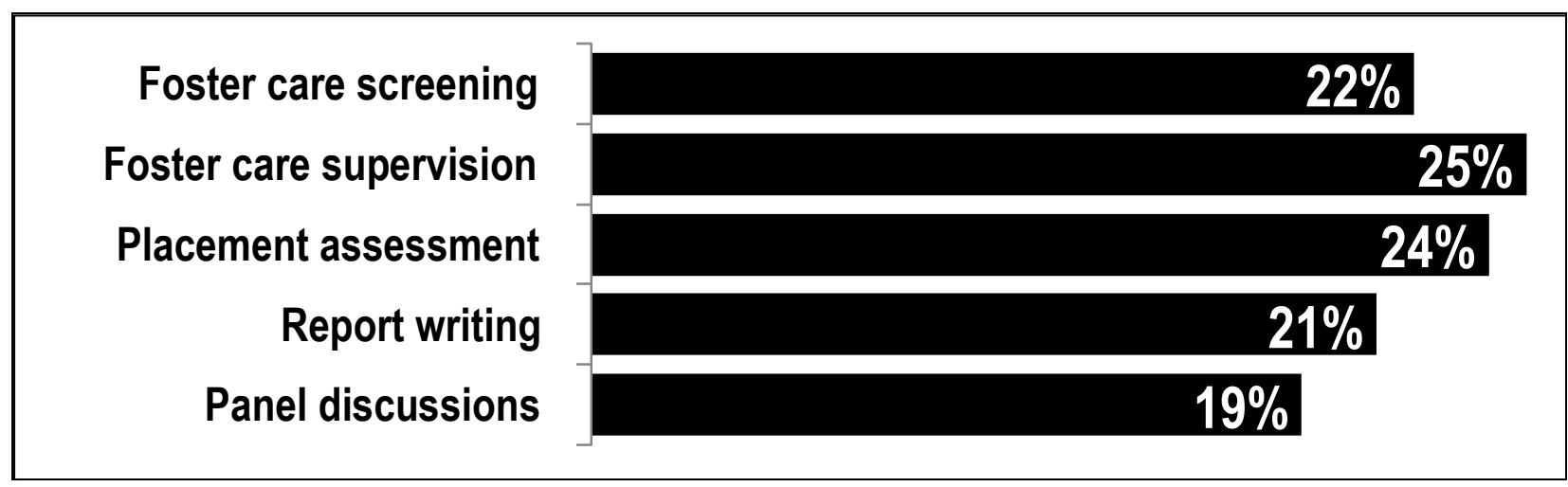

\section{CROSS-REFERENCE OF ATTACHMENT THEORY KNOWLEDGE AND USE WITH YEARS OF EXPERIENCE}

The data indicated that there might be a correlation between years of experience and knowledge and use of attachment theory. These variables were cross-referenced with the following result description.

TABLE 6

CROSS-REFERENCE OF YEARS OF EXPERIENCE AND KNOWLEDGE AND USE OF ATTACHMENT THEORY

\begin{tabular}{|l|c|c|c|c|c|c|c|c|c|c|}
\hline Experience $\mathbf{n = 1 7}$ & \multicolumn{2}{|c|}{$\mathbf{0 - 3}$ Years=10 } & \multicolumn{2}{|c|}{ 4-6 Years=1 } & \multicolumn{2}{|c|}{ 7-9 Years $=1$} & \multicolumn{3}{|c|}{$\mathbf{1 0 - 1 2}$ Years=2 } & \multicolumn{3}{c|}{ 12< Years=3 } \\
\hline Attachment Theory & Know & Use & Know & Use & Know & Use & Know & Use & Know & Use \\
\hline Percentage & $26 \%$ & $10 \%$ & $21 \%$ & $17 \%$ & $0 \%$ & $0 \%$ & $48 \%$ & $49 \%$ & $30 \%$ & $42 \%$ \\
\hline
\end{tabular}

The cross-reference between years of experience and the respondents' knowledge and use of attachment theory revealed that there is a positive correlation between years of experience and their knowledge and use of attachment theory. The higher the number of years of experience, the higher the score of their knowledge and use. The respondents with between 10 and 12 years of experience scored $48 \%$ for knowledge and $49 \%$ for use, which was the highest among all the categories measured. The lowest score measured was for the group 7-9 years, which had one respondent who fell within this category. This respondent mentioned in her interview that she had not been trained in any of the theoretical components of attachment theory.

The differences between the knowledge and use measurement also yielded significant data. Among the 0-3 years of experience group the knowledge component (26\%) measure was $16 \%$ higher than their use measure $(10 \%)$. This might indicate that this group, which had graduated most recently, had more theoretical knowledge transferred but were lacking in application because of less field experience. The difference between their knowledge $(21 \%)$ and their use $(17 \%)$ decreased to $4 \%$ in the group with 4-6 years of experience. The discrepancy between their knowledge and use measurement decreased, but the total scores remained in the lower percentage range. This could indicate that they are still ill equipped to assess and address attachment-based issues.

In the group of 10-12 years of experience the difference between their knowledge component $(48 \%)$ and their use component was $1 \%$, with their use exceeding their knowledge. This group 
tested highest in post-qualification training, which may account for their higher knowledge score and they may have sufficient field experience to value the importance of attachmentrelated issues within the field of social work. The difference between the knowledge (30\%) and the use component (42\%) of $12 \%$ among the $12<$ group, with their use again exceeding their knowledge, indicates that their theoretical knowledge may have stagnated, while their use of what they did know increased. It should be noted that the actual years of experience of this group all exceeded 22 years of social work experience and the questionnaire did not make provision for categories exceeding 12 years.

\section{Perception and self-evaluation of the application of attachment theory components}

The respondents were asked to comment on whether they agreed, were not sure or disagreed on a given statement reflecting their personal experience and opinion regarding real-life foster care situations where attachment theory components and attachment-related issues were present. These questions were asked in order to measure their in-practice use of attachment theory, where knowledge of the specific wording such as "disorganised attachment" was not important. The measurements were again taken across the axes of "knowledge" and "use" of attachment theory in their in-practice experience. A third measurement was taken of the respondents' views of practice constraints which prevent the use of attachment theory.

\section{PERCEPTION OF KNOWLEDGE THROUGH IN-PRACTICE EXPERIENCE}

\section{Knowledge of attachment theory}

Fifty-three percent $(53 \%)$ of the respondents reported that they did not have enough knowledge of attachment theory and $24 \%$ reported that they were unsure. Only $24 \%$ were satisfied with their level of knowledge of attachment theory (Figure 4). The average score of the knowledge of attachment theory was $24 \%$ (Table 5), which suggests that some of the respondents held an inflated view of their knowledge of attachment theory.

\section{Attachment forms naturally between a foster parent and a child}

Forty-seven percent (47\%) disagreed with this statement, while $35 \%$ of participants were unsure and $18 \%$ agreed. Current research suggests that attachments do form naturally - "all children will form some attachment regardless of the depravity of the environment" (Peluso et al., 2004:140). The attachment that does form may not necessarily be secure. The attachment between a foster parent and a child is more at risk of being insecure as a result of various negative factors that may have an influence such as familial instability, prior abuse and parental substance abuse (Harden, 2004:35). The response to this question again indicates the lack of knowledge regarding attachment theory.

\section{Attachment does not play a role in the foster placement outcome}

Insecure attachments between the foster parent and child have been positively linked to placement breakdown (Chamberlain et al., 2001:200; Green, 2003:209). The respondents displayed insight into the influence of attachment on a foster placement - eighty-two percent $(82 \%)$ disagreed with this statement. This insight does not seem to be grounded in their knowledge of attachment theory, but may rather indicate a "common sense" approach when responding to the research questions.

\section{The younger the age of the child at the time of the placement the better the attachment}

Seventy-six percent (76\%) of the respondents agreed with this statement. Although younger children do attach more easily, their young age is not the only predictor of a secure attachment. Haight et al. (2003:195) reflect on Crittenden and Ainsworth (1989) in Cicchetti and Carlson 
(1998), who found that attachment relationships the infant formed up to the age of three years are likely to influence subsequent relationships and their effects are likely to carry on into adulthood. The ability of the social worker to identify and address the type and quality of the attachment patterns within the foster placement, even for young children, remains essential.

\section{Prior abuse does not influence the ability of the child to attach}

Eighty-two percent (82\%) of the respondents disagreed with this statement. Prior abuse, including previous placement breakdowns, is predictive of attachment difficulties of insecure attachment patterns of children in foster care (Chamberlain et al., 2001:200; Haight et al., 2003:197). The in-practice experience of the respondents has led them to concur with current research that prior abuse does influence the child's ability to attach. It would seem that the respondents knew that prior abuse had the potential of impacting negatively on the placement of the child. However, it does not seem from the current study that respondents have the knowhow to pinpoint or address the attachment-based problems in the cases they supervise.

\section{FIGURE 4 \\ PERCEPTION OF KNOWLEDGE ATTACHMENT THEORY THROUGH "IN PRACTICE" EXPERIENCE}

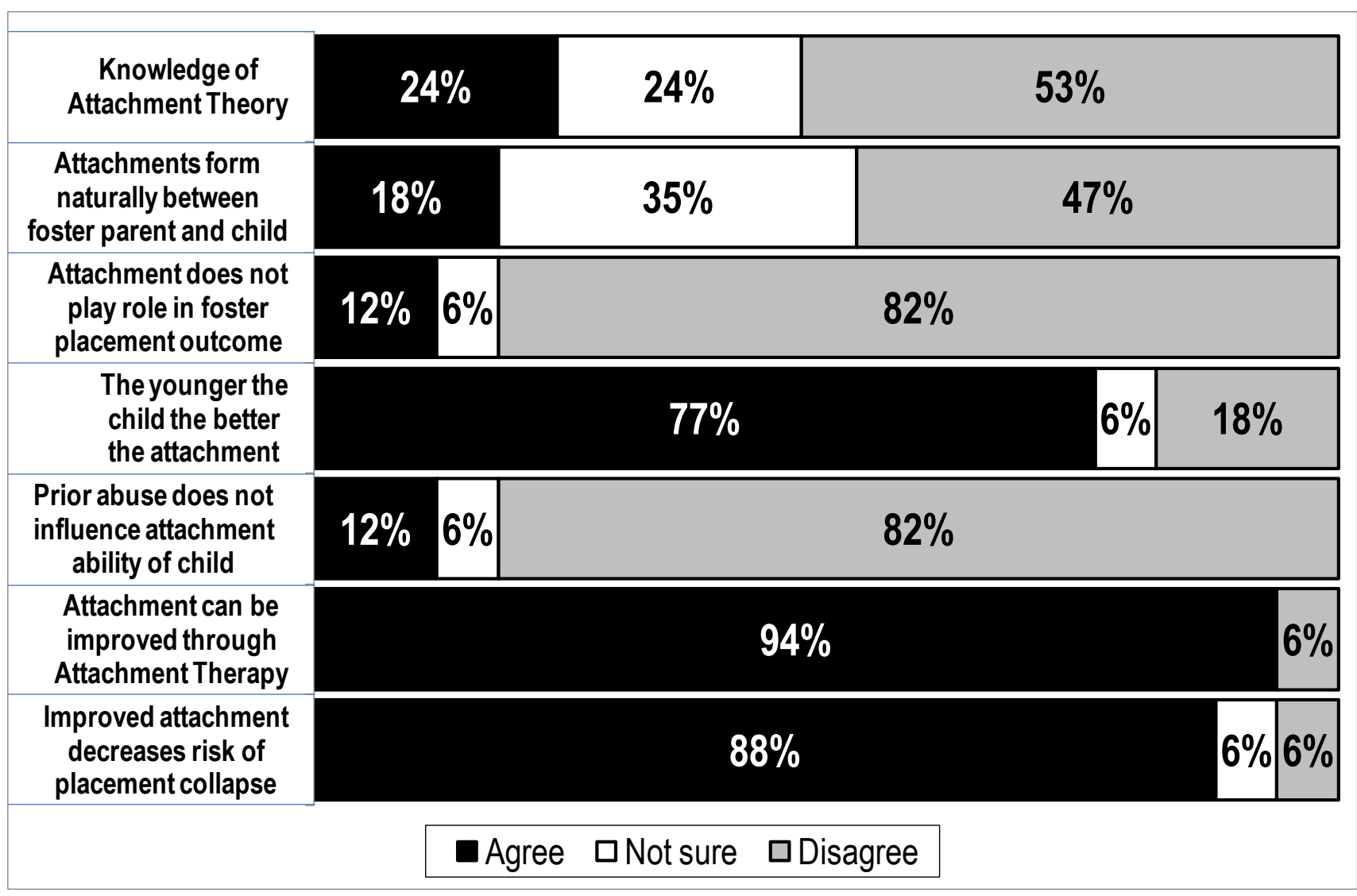

\section{Attachment can be improved by attachment therapy}

Ninety-four percent $(94 \%)$ of the respondents agreed with this statement. Various attachment theory-based therapy methods have been developed in recent years such as theraplay (Jenberg \& Booth, 2005) and family attachment narrative therapy (May, 2005:81-99). The question arises whether children in foster care have access to such therapies and whether the social workers are trained to provide them to the clients. The respondents concur with the findings of recent studies which hold that attachment therapy could improve the foster parent-child relationship (Jenberg \& Booth, 2005:31; May, 2005:81; Velderman in Newman \& Mares, 
2007:345-346). Their statement may reflect a belief that attachment therapy can improve the attachment between the parent and the child rather than an experiential reality in their current environment.

\section{Improved attachment decreases the risk of placement collapse}

Eighty-eight percent (88\%) of the respondents agreed with this statement. The proponents of the attachment-based therapies have researched and reported positively on the effectiveness of their therapy models to address attachment difficulties and prevent placement collapse (Jenberg \& Booth, 2005:31; May, 2005:81).

\section{Self-evaluation of in-practice attachment theory use}

The respondents' self-evaluation of their in-practice use of attachment theory was contrasted with their reported use of the theoretical concepts (Figure 5). The respondents reported (Table 5) that they use attachment theory $20 \%$ on average in foster care supervision as discussed earlier. The following five statements were made regarding their in-practice use of attachment theory:

\section{I am able to identify the attachment pattern of a child}

Sixty-five percent $(65 \%)$ of the respondents agreed with this statement. However, the measurement of the theoretical components of attachment theory revealed that only $21 \%$ of them have heard of the concept of attachment pattern and that $15 \%$ of them have used it in foster care supervision. It would seem that they evaluate their in-practice knowledge and use of the concept of "attachment patterns" higher than their theoretical knowledge actually is.

\section{I consider the attachment pattern of the child when placing him/her in foster care}

Eighty-eight percent $(88 \%)$ of the respondents agreed with this statement. This implies that the respondents were mindful of attachment issues when placing a child in foster care. It also indicates that the social workers consider themselves to be able to identify the attachment pattern of the child and to factor it in as part of the matching process between the child and the prospective foster parent. From the preceding discussion it seems that the social workers lacked the basic knowledge of what an attachment pattern refers to. It also is evident that the social workers are not adequately trained to make such evaluations (Table 5).

\section{My current level of knowledge concerning attachment theory would allow me to enrich the quality of attachment between foster parents and child}

Fifty-nine percent $(59 \%)$ of the respondents agreed with this statement and $18 \%$ were not sure. The average score of attachment theory knowledge (24\%) and use (20\%), as mentioned earlier, contradicts their self-evaluation of their in-practice use of attachment theory. The generally low scores measured on both axes of knowledge and use indicate that the respondents do not have sufficient knowledge of attachment theory.

\section{I feel confident in assessing the attachment between foster parent and child}

Fifty-three percent $(53 \%)$ of the respondents agreed with this statement. The "strange situation" is one of the primary and well-researched assessment methods of determining the attachment pattern between a primary caregiver and a child. The respondents reported that only $7 \%$ of them had heard of it and only $1 \%$ use was reported. The researcher postulates that the respondents may be able to determine in generic terms whether the attachment between a foster parent and child is good or bad, but do not actually assess the attachment in terms of the parameters and concepts of attachment theory. 


\section{I feel confident about doing attachment therapy}

Only $35 \%$ of the respondents agreed with this statement, $47 \%$ were unsure and $18 \%$ evaluated themselves as not being confident about their ability to do attachment therapy. This response was a strong indication of the insecurity of the respondents regarding their ability to use knowledge specifically associated with attachment-based interventions and therapy. This score is more in line with the scores measured for the knowledge and use of the theoretical components of attachment theory.

\section{I have moved children out of a foster placement because there were attachment problems between the child and foster parents}

Seventy-one percent $(71 \%)$ of the respondents agreed with this statement. This score indicates that the respondents have identified attachment issues as a reason for placement collapse, a factor which is supported by recent research (Chamberlain et al., 2001; Harden, 2004). It would seem from the participants' responses that their self-evaluation of their in-practice use of attachment theory is generally much higher, ranging between $35 \%$ and $88 \%$, than their measured use of theoretical components, which was $20 \%$ on average (ranging between $1 \%$ and $43 \%)$.

The social workers reported that they were able to use theoretical components in practice which they had reported that they knew very little about ("Knowledge of theoretical components" averaged $24 \%$, ranging between $7 \%$ and $38 \%$ ). This discrepancy possibly indicates that they are of the opinion that they know and use the theoretical components of attachment theory, but that their knowledge is rather based on their own perceptions (common-sense understanding) of attachment theory than its actual definitions.

FIGURE 5

SELF-EVALUATION OF IN-PRACTICE USE OF ATTACHMENT THEORY

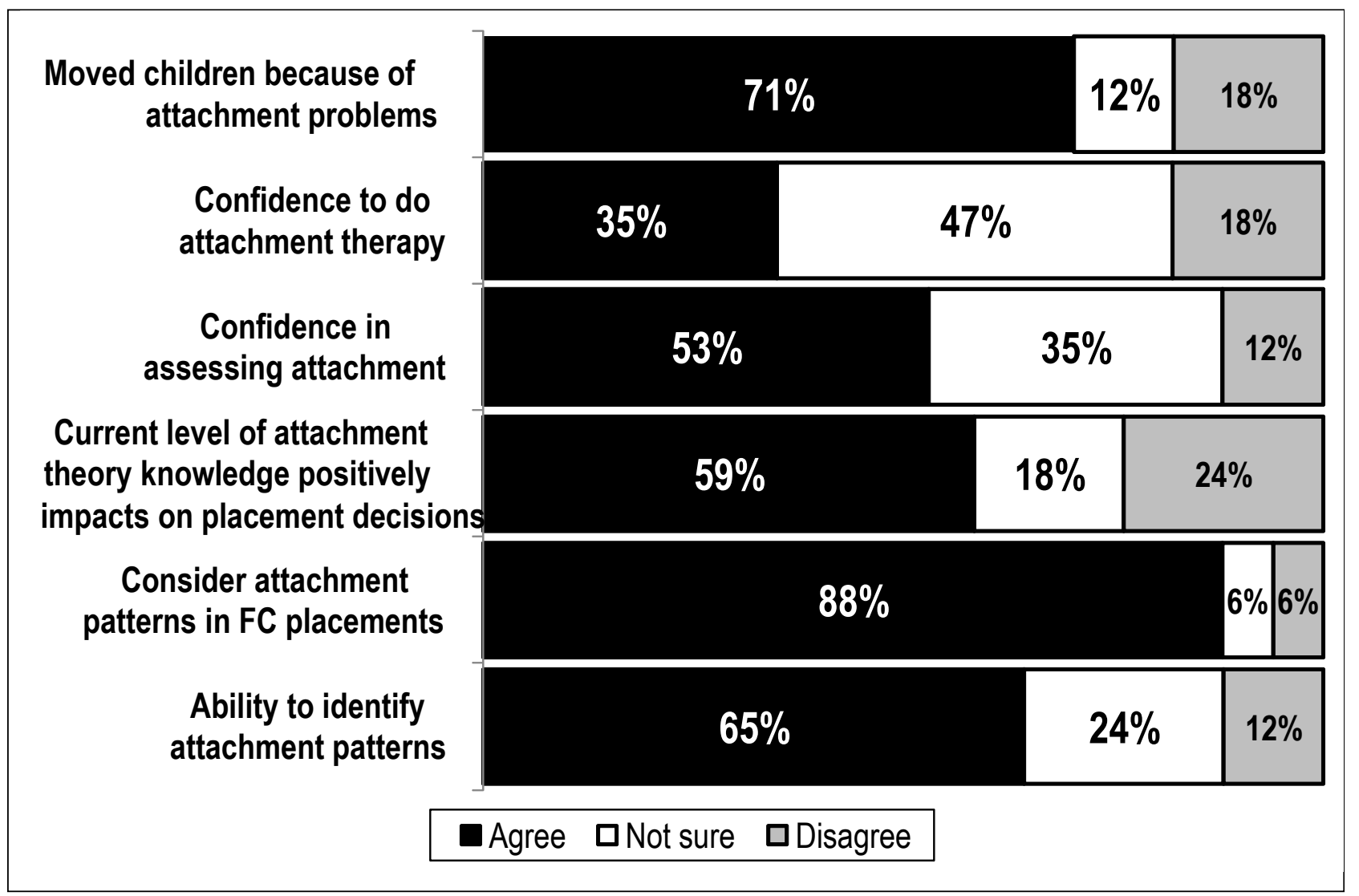




\section{In-practice constraints preventing the application of attachment theory}

The environments in which foster care supervision services are rendered often have crippling implications for the quality of service provision. Three possible constraints, namely a high foster care case load, the pressure to find new foster placements and time limitations due to high case loads, were explored.

\section{If the foster care placement of the child meets his/her physical and educational needs but I were not sure of the attachment possibilities, I would still place the child}

According to SASSA there are currently 454199 children in foster care, with a backlog of 157000 (Parliamentary Monitoring Group, 2009). The in-practice reality is that there are often not enough foster parents available to place children, and social workers may have no alternative but to place a child in a home where their basic needs are met without giving thorough attention to the attachment needs of the child.

Twenty-nine (29\%) of the respondents indicated that they would still place a child even if their attachment needs are not met, and a further $29 \%$ were unsure. This indicates that $59 \%$ of the respondents may make decisions based on the circumstances involved in the case rather than on the principle of providing a physically and emotionally secure placement for a child. Another possibility is that they might not have the knowledge or experience of the importance of the attachment needs of a child when developing and supervising a placement. Forty-one (41\%) of the respondents disagreed with this statement, reflecting their concern for the attachment needs of the child when placing him/her in foster care.

\section{The need to find new foster placements does not allow me time to consider the attachment needs of the child}

Eighteen percent (18\%) of the respondents concurred and said that they experience pressure to find new foster parents for children entering the system. A significant percentage reported that they were unsure $(35 \%)$, which may indicate that they might not have determined attachmentrelated issues as a priority. A total of 53\% therefore felt that they could not address the attachment needs of their clients. Forty-seven (47\%) disagreed with this statement, indicating that they did not consider the pressure of finding new foster parents as a reason for not paying attention to the child's attachment needs.

\section{Due to my high case load I do not have time to address the attachment between the foster parent and the child}

High case loads are a South African reality and do pose a challenge for service delivery (Department of Social Development, 2006; Naidoo \& Kasiram, 2006). Fifty-three percent (53\%) of the respondents felt that their high case loads prevented them from addressing the attachment needs of their clients and 6\% were unsure. A combined total of 59\% seemed to be negatively affected by their high case loads. This measurement reflects the in-practice reality that the respondents do not always have the time to pay attention to attachment-related issues while doing foster care supervision. A significant percentage of the respondents reported that they did not agree with this statement $(41 \%)$, which may indicate that they consider attachment as a priority in spite of their high case load. These respondents could possibly be reflecting on the tension between their moral obligations to consider the attachment needs of the children in spite of their high case loads. 
FIGURE 6

IN-PRACTICE CONSTRAINTS THAT PREVENT THE USE OF ATTACHMENT THEORY

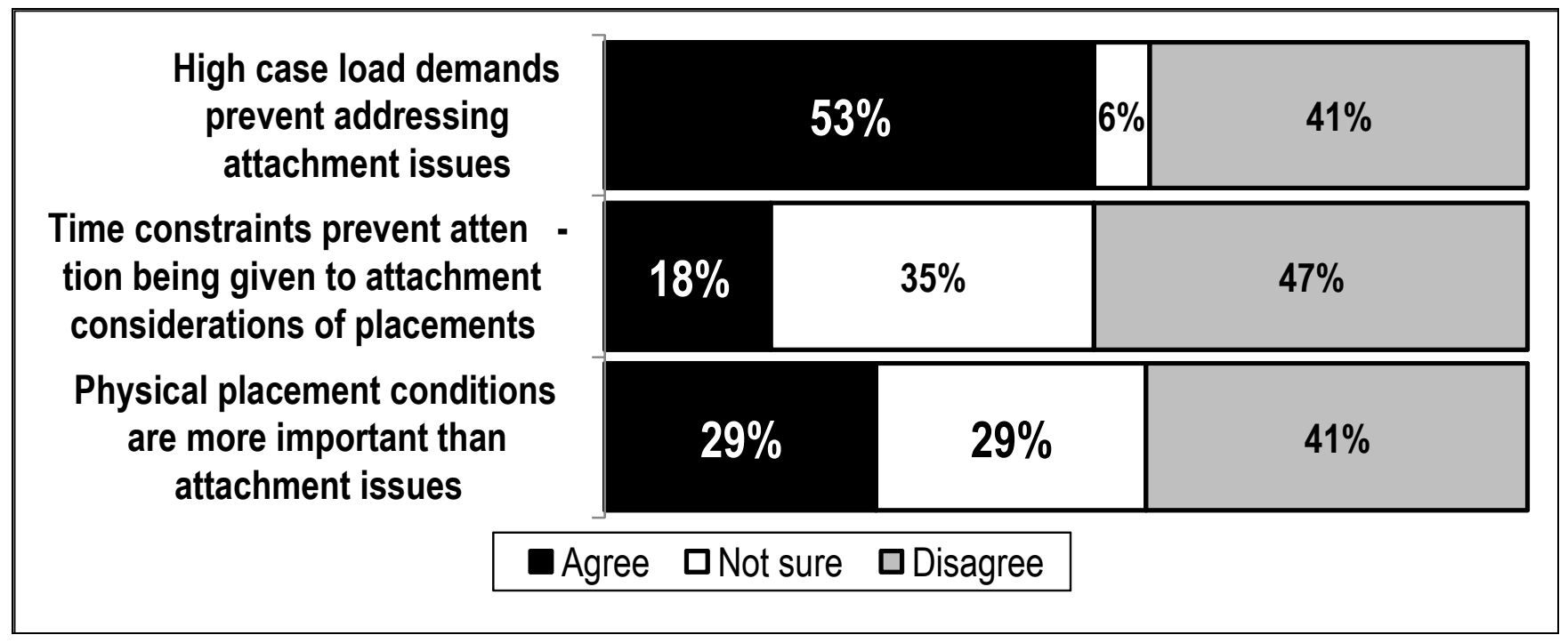

\section{DISCUSSION}

The value of attachment theory in the context of foster care has been well documented. The insight that attachment theory has brought to understanding and enriching the relationship between the foster parent and the child has particular application potential within the social work field. In this paper the researchers explored the utilisation of attachment theory by social workers in foster care supervision. Central to the research has been the statement that social workers currently doing foster care supervision do not have adequate knowledge of attachment theory, nor do they apply this knowledge in practice. It is important to bear in mind, however, that attachment theory is a specialised field of training and not usually part of undergraduate training.

The finding that the Child Welfare Tshwane social workers did not feel adequately equipped with regard to attachment theory is thus not surprising. They had a "common sense" approach to understanding and addressing attachment-related issues, but lacked the theoretical knowledge to underpin their efforts to address the attachment between the foster parent and the child. The generally low scores related to the theoretical components compared to the respondents' higher self-evaluation scores of their in-practice knowledge and use of attachment theory revealed that they are unable to identify and address the attachment needs of their clients. It seemed that they were largely under a false impression of their actual ability to deal with attachment-related issues. These research results could indicate that the attachment-related needs of clients are to a large extent left unattended.

Harden (2004:41) argues that it is "imperative for the welfare system to move beyond a singular focus on safety and permanency and to promote the well-being of children in custodial care". By casting a wider net that includes knowledge of attachment theory in foster care supervision, social workers would be enabled to better evaluate the quality of care and align support and other interventions to address the needs of the foster child and family, thus moving towards a greater sense of wellness. Within the South African context there seems to be an opportunity to determine how cultural differences are shaping the attachment relationships in kinship care and foster placements. Haight et al. (2003:200) are of the opinion that 
"understanding universal aspects of attachment relationships, as well as the ways in which such relationships develop within particular social and cultural groups, provides a foundation for recognising any problematic aspects of parent-child attachment relationships". To be able to accomplish this, social workers should be trained in attachment theory and its implications for the field of social work in delivering services to children and families. This can be part of the undergraduate and/or in-service training.

The effects of the current loss of skilled social workers to government departments and the private sector in child welfare is evident in the high number of staff with little social work and foster care experience. This, along with the limited knowledge and use of attachment theory and the identified practical constraints, may not be unique to Child Welfare Tshwane. Other social work NGOs could be faced with similar conditions which impact negatively on the quality of foster care supervision. The results of this study therefore could create awareness in other welfare organisations of the need to better equip their social work staff with attachment theory knowledge.

In conclusion, the researchers concur with Haight et al. (2003:196) that "understanding several aspects of attachment relationships [and attachment theory] can guide social workers to developmentally and culturally sensitive practice, as well as provide a foundation for recognising problems in attachment relationships". It is the researchers' view that, by considering the attachment needs of clients, we can improve the quality of foster care supervision and the general foster care experiences of the children we work with.

\section{RECOMMENDATIONS}

In order to better equip social workers to deal with attachment-related issues in foster care services, it is necessary that:

- this study be repeated with a larger sample size and include social workers from a variety of organisations in order to generalise the findings to the field of social work;

- a second study be anchored to actual measures of the use of attachment theory application by, for example, drawing upon real foster care supervision case studies;

- Child Welfare Tshwane extends its in-service training programme to include focused training on attachment theory;

- appropriate attachment-sensitive interventions be developed and made available to the client base of Child Welfare Tshwane to provide support to the children and parents in foster care placements;

- the South African Council of Social Service Professions (Education and Development), consider the inclusion of attachment theory in the social curriculum at university level to ensure more extensive knowledge and use of attachment theory within the social work context.

\section{CONCLUSION}

Attachment theory has re-emerged as an important field of study within the social work context. This study revealed that the social workers of Child Welfare Tshwane have a common sense sensitivity to attachment-related issues, but lack the thorough theoretical grounding in attachment theory to address them successfully. These researchers postulate that adequate training regarding attachment theory would make a positive impact on the quality of foster care supervision within the Child Welfare Tshwane and other organisations. 


\section{REFERENCES}

AMERICAN PSYCIATRIC ASSOCIATION. 2000. Diagnostic and statistical manual of mental disorders: DSM-IV-TR. Washington, DC: American Psychiatric Association.

ACHENBACH, T.M. 1991. Manual for the child behavioural check list / 4-18 and 1991 profile. Burlington Vermont: University of Vermont, Department of Psychiatry.

ACKERMAN, J.P. \& DOZIER, M. 2005. The influence of foster parent investment on children's representations of self and attachment figures. Applied Developmental Psychology, 26:207-520.

AINSWORTH, M.D., BELHAR, M.C., WATERS, E. \& WALL, S. 1978. Patterns of attachment: a psychological study of the strange situation. Hillsdale, NJ: Lawrence Erlbaum Associates.

BARTH, R.P., CREA, T.M., JOHN, K., THOBURN, J. \& QIUNTON, D. 2005. Beyond attachment theory and therapy: towards sensitive and evidence-based interventions with foster and adoptive families in distress. Child and Family Social Work, 10:257-268.

BELSKY, J. \& NEZWORSKI, T. 1988. Clinical applications of attachment. In: BELSKY, J. \& NEZWORSKI, T. (eds) Clinical applications of attachment. Hillsdale New York: Elbaum: 3-17.

BOWLBY, J. 1969. Attachment and loss (vol 1). London: Hogarth Press.

CHAMBERLAIN, P., SMITH, D.K., STORMSHAK, E. \& BRIDGES-WHALEY, R. 2001. Placement disruption in treatment foster care. Journal of Emotional and Behavioural Disorders, 9(3):200-205.

CICCHETTY, D. \& CARLSON, V. (eds). 1998. Child maltreatment: theory and research on the causes and consequences of child abuse and neglect. New York: Cambridge University Press.

DELPORT, C.L.S. 2005. Quantitative data collection methods. In: DE VOS, A.S. (ed) Research at grass roots: for the social sciences and human service professions $\left(3^{\text {rd }}\right.$ ed). Pretoria: Van Schaik Publishers: 159-190.

DEPARTMENT OF COMMUNITY SERVICES NEW SOUTH WHALES. 2006. Key messages from research. The importance of attachment in the lives of foster children. Centre for Parenting and Research, Research Funding and Business Analysis Division. New South Whales: Ashfield.

DEPARTMENT OF SOCIAL DEVELOPMENT. 2005. Assessment of the NPO act. Pretoria: Republic of South Africa.

DEPARTMENT OF SOCIAL DEVELOPMENT. 2006. Draft recruitment and retention strategy for social workers. Pretoria: Republic of South Africa.

DOGGETT, R.A., RENFRO-MICHEL, E.L. \& SHEPERIS, C.J. 2003. In-home treatment of reactive attachment disorder in a therapeutic foster care system: a case example. Journal of Mental Health Counselling, 25:76-88.

FOUCHÉ, C.B. \& DE VOS, A.S. 2005. Problem formulation. In: DE VOS, A.S. (ed) Research at grass roots: for the social sciences and human service professions $\left(3^{\text {rd }}\right.$ ed). Pretoria: Van Schaik Publishers: 100-110.

GOOSSENS, F.A., VAN IJZENDOORN, M.H., TAVECCHIO, I.W.C. \& KROONENBERG, P.M. 1986. Stability of attachment across time and context in a Dutch sample. Psychological Reports, 58:23-32. 
GREEN, V. 2003. Emotional development in psychoanalysis, attachment theory, and neuroscience: creating connections. New York: Brunner-Routledge.

HAIGHT, W.L., KAGEL, J.D. \& BLACK, J.E. 2003. Understanding and supporting parentchild relationships during foster care visits: attachment theory and research. Social Work, 48(2):195-207.

HARDEN, B.J. 2004. Safety and stability for foster children: a developmental perspective. The Future of Children, 14:31-47.

HOWE, D., BRANDON, M., HININGS, D. \& SCHOFIELD, G. 1999. Attachment theory, child maltreatment, and family support: a Practice and Assessment Model. New Jersey: Lawrence Erlbaum Associates.

JENBERG, A.M. \& BOOTH, P.B. 2005. Theraplay: helping parents and children build better attachments through attachment based play $\left(2^{\text {nd }} \mathrm{ed}\right)$. San Francisco: Josey Boss Publishers.

LIEBERMAN, A.E. \& PAWL, J.H. 1988. Clinical applications in attachment theory. In: BELSKY, J. \& NEZWORSKI, T. (eds) Clinical applications of attachment. Hillsdale New York: Elbaum: 327-351.

MAY, J.C. 2005. Family attachment narrative therapy: healing the experience of early childhood maltreatment. Journal of Marital and Family Therapy, 81-99.

MINNIS, H., MARWICK, H., ATHUR, J. \& McLAUGHLIN, A. 2006. Reactive attachment disorder - a theoretical model beyond attachment. Child and Adolescent Psychiatry, 15:336-342.

NAIDOO, S. \& KASIRAM, M. 2006. Experiences of South African social workers in the United Kingdom. Social Work/Maatskaplike Werk, 42(2):117-146.

NEWMAN, L. \& MARES, S. 2007. Resent advances in the theories and with interventions with attachment disorders. Current Opinions in Psychiatry, 20(4):343-348.

PARLIAMENTARY MONITORING GROUP. 2009. South African Social Security Agency Annual Report 2007/08: briefing. [Online] Available: http://www/pmg.org.za/print/15274 [Accessed: 02-04-2009].

PELUSO, J.P., PELUSO, P.R., KERN, R.M. \& WHITE, J.F. 2004. A comparison of attachment theory and individual Psychology: a review of literature. Journal of Counselling and Development, 82:139-145.

SHEPERIS, C.J., BLANCHARD, T., DOGGETT, R.A., HODA, N.E., RENFRO-MICHEL, E.L. \& SCHLAGHECK, R. 2003. The development of an assessment protocol for reactive attachment disorder. Journal of Mental Health Counselling, 25:291-310.

SROUFE, L.A. 1988. The role of infant care-giver attachment in development. In: BELSKY, J. \& NEZWORSKI, T. (eds) 1988. Clinical implications of attachment. Hillsdale, NJ: Lawrence Erlbaum Associates: 18-38.

STONE, N. \& STONE, S. 1983. The prediction of successful foster placement. Journal of Contemporary Social Work, 1:11-17.

Ms Wezet Botes, Therapy and Adoption Unit, Child Welfare Tshwane, Pretoria; Dr Elma Ryke, School of Psychosocial Behavioural Sciences (Social Work), North-West University Potchefstroom Campus, South Africa. 